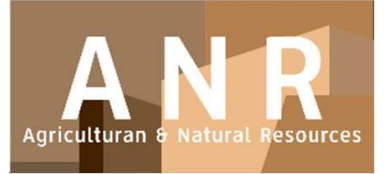

PAPER - OPEN ACCESS

\title{
Perbandingan Riap Diameter Tegakan Hutan Di Jalur Tanam Dengan Di Jalur Antara Pada Sistem Silvikultur TPTJ
}

\author{
Author $\quad:$ M. Taufan Tirkaamiana \\ DOI $\quad: 10.32734 /$ anr.v3i1.840 \\ Electronic ISSN : :2654-7023 \\ Print ISSN : $2654-7015$
}

Volume 3 Issue 1 - 2020 TALENTA Conference Series: Agriculturan \& Natural Resource (ANR)

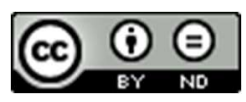

This work is licensed under a Creative Commons Attribution-NoDerivatives 4.0 International License.

Published under licence by TALENTA Publisher, Universitas Sumatera Utara

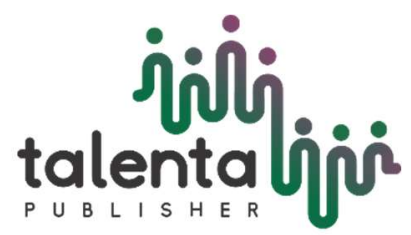




\title{
jibiti

\section{Perbandingan Riap Diameter Tegakan Hutan Di Jalur Tanam Dengan Di Jalur Antara Pada Sistem Silvikultur TPTJ}

\author{
M. Taufan Tirkaamiana ${ }^{a}, *$ \\ ${ }^{a}$ Prodi Kehutanan, Fakultas Pertanian, Universitas 17 Augustus 1945 Samarinda, Jl. Ir. H. Juanda 80 Tel./Fax. +62-541-743390, Samarinda \\ 75124, Kalimantan Timur, Indonesia \\ taufan_ta@yahoo.co.id,taufan@untag-smd.ac.id
}

\begin{abstract}
Abstrak
Dalam mengusahakan hutan produksi khususnya yang dikelola dengan sistem silvikultur Tebang Pilih Tanam Jalur (TPTJ) dari suatu unit manajemen, dianut asas kelestarian hasil (sustained yield principle). Apabila besarnya etat volume kayu sama dengan riap, yaitu besarnya volume kayu yang tumbuh pada seluruh tapak dalam waktu satu tahun, maka kelestarian hasil dari suatu unit manajemen akan dapat dicapai. Penelitian ini bertujuan untuk mengetahui perbedaan riap diameter tegakan Dipterocarpaceae pada jalur tanam dengan jalur antara di areal izin konsesi PT Balikpapan Forest Industries di Kabupaten Penajam Paser Utara, Kalimantan Timur Indonesia. Data riap diameter tegakan diperoleh dengan cara mengamati 4 (empat) Petak Ukur Permanen (PUP) dimana masing-masing PUP berukuran $100 \mathrm{~m}$ x $100 \mathrm{~m}$. Berdasarkan hasil penelitian diketahui rataan riap diameter tegakan Shorea leprosula di jalur tanam sebesar 2,08 cm/th, sedangkan tegakan jenis komersil pada jalur antara sebesar 1,08 cm/th. Hasil uji statistik dengan uji-t menunjukkan bahwa perbedaan riap diameter antara tegakan Dipterocarpaceae di jalur tanam dengan tegakan jenis komersil di jalur antara tidak menunjukkan perbedaan yang signifikan. Di jalur antara faktor yang menghambat pertumbuhan antara lain : jenis yang beragam, faktor genetik, kerapatan yang tidak teratur, dan persaingan hara. Sedangkan di jalur tanam faktor yang mempercepat pertumbuhan antara lain : intensitas cahaya yang merata, berkurangnya persaingan hara, dan faktor genetik.
\end{abstract}

Kata Kunci: Faktor genetic; Jalur Antara; Jalur tanam; riap; kerapatan

\section{Pendahuluan}

Salah satu upaya meningkatkan produktivitas dan kualitas hutan tropis di Indonesia adalah melalui sistem Tebang Pilih Tanam Jalur (TPTJ) atau sebelumnya disebut Tebang Pilih Tanam Indonesia Intensif (TPTII) atau dikenal dengan SILIN (silvikultur intensive) yaitu suatu sistem silvikultur yang menerapkan prinsip-prinsip dasar silvikultur intensif yang terdiri dari pemuliaan pohon, manipulasi lingkungan dan perlindungan terhadap serangan hama penyakit.

Dalam mengusahakan hutan produksi khususnya yang dikelola dengan TPTJ dari suatu unit manajemen, dianut asas kelestarian hasil (sustained yield principle). Apabila besarnya etat volume kayu sama dengan riap, yaitu besarnya volume kayu yang tumbuh pada seluruh tapak dalam waktu satu tahun, maka kelestarian hasil dari suatu unit manajemen akan dapat dicapai.

Keberlanjutan hutan tropis merupakan salah satu perhatian Pemerintah. Untuk mencapai tujuan itu, tiga sistem silvikultur yaitu Tebang Pilih Indonesia (TPI), Tebang Pilih Tanam Indonesia (TPTI), dan Tebang Pilih Tanam Jalur(TPTJ) telah diterapkan [1]. Untuk mengatasi masalah produktivitas dan sekaligus pengembangan hutan tanaman, ilmu kehutanan mengenal istilah Hutan Prospektif. Prospektif dalam hal ini memiliki pengertian 
produktivitasnya tinggi, pemanfaatannya efisien, pengelolaannya efektif, ekosistemnya stabil, dan biodiversitas tinggi. Salah satu teknik yang digunakan untuk menembangkan hutan prospektif adalah silvikultur intensif [2].

Sejak tahun 2005 di Indonesia telah dilakukan plot pembangunan tanaman meranti dengan teknik Silin yang dicobakan di 6 IUPHHK calon model. Hasil sementara, dengan spesies target yang tepat dan keterbukaan terhadap naung yang cukup, diperkirakan riap tanaman sekitar $10 \mathrm{~m}^{3} / \mathrm{ha} /$ th misalnya dengan spesies target Shorea leprosula, $S$. parvifolia, dan S. johorensis [3]. Shorea leprosula, S. platyclados, S. parvifolia dan S. Johorensis juga cocok dipilih sebagai jenis penanaman pada penanaman pengayaan tebang pilih dan sistem silvikultur penanaman baru, karena tanpa penanaman pengayaan dengan spesies yang sesuai, hutan hujan tropis akan masuk tahap degradasi dan fragmentasi [4].

Penelitian yang berkaitan dengan produktivitas tegakan dalam sistem TPTJ umumnya lebih banyak meneliti kepada tanaman yang ditanam di jalur tanam, dan jarang meneliti tegakan-tegakan tinggal di jalur antara. Atas dasar ini, maka penelitian tentang produktivitas tegakan di jalur antara dan membandingkannya dengan tanaman di jalur tanam pada sistem TPTJ sangat diperlukan untuk menyusun rencana pengusahaan hutan dengan asas kelestarian hasil. Penelitian ini bertujuan untuk mengetahui perbandingan riap diameter tegakan Dipterocarpaceae yang ditanam di jalur tanam dengan riap diameter tegakan tinggal Dipterocarpaceae di jalur antara pada sistem TPTJ di areal IUPHHK PT Balikpapan Forest Industries di Kabupaten Penajam Paser Utara, Provinsi Kalimantan Timur. Melalui penelitian ini diharapkan dapat diketahui perlakuan silvikultur yang optimal untuk meningkatkan produktifitas hutan dengan jenis tanaman dari family Dipterocarpaceae pada sistem TPTJ.

\section{Metode Penelitian}

\subsection{Lokasi Penelitian}

Penelitian ini dilaksanakan di jalur tanam dan di jalur antara pada blok TPTJ di areal PT Balikpapan Forest Industries (BFI) di Kabupaten Penajam Paser Utara, Provinsi Kalimantan Timur (116 23'57'BT, 17'15'LS). Sistem silvikultur yang digunakan dalam pengelolaan kawasan hutan produksi adalah sistem tebang pilih tanam jalur di mana batas limit diameter yang boleh ditebang adalah $40 \mathrm{~cm}$ ke atas [7] dan permudaan buatan dilakukan untuk mencapai hutan menggunakan dipterocarpaceae terpilih dalam sistem penanaman jalur [8] Tipe iklim di lokasi penelitian adalah tipe A (Schmit dan Ferguson) di mana rata-rata curah hujan tahunan adalah 2,316 mm per tahun dan jumlah hujan rata-rata adalah 125 hari per tahun. Bahan yang digunakan dalam penelitian ini adalah tegakan jenis S.leprosula dan D. lanceolata umur 1 tahun sampai dengan 7 tahun pada jalur tanam dan tegakan jenis komersil dan non komersil di jalur antara (bekas tebangan Et-1 s.d. Et-5) dalam blok TPTJ di areal PT BFI. Peralatan yang digunakan adalah: peta kerja, phiband, alat GPS (Global Position System) tipe Garmin 60Csx, kompas, shunto, clinometer, dan pita ukur jarak.

\subsection{Prosedur Penelitian}

Untuk menentukan pertumbuhan dan riap diameter tegakan yang ditanam di jalur tanam (S. leprosula dan $D$. lanceolata umur 1 tahun sampai 7 tahun) dan di jalur antara (tegakan tinggal jenis komersil dan non komersil) di blok TPTJ, parameter diameter pohon diukur di 2 PUP (Petak Ukur Permanen) di mana setiap PUP memiliki ukuran masing-masing $100 \mathrm{~m}$ x $100 \mathrm{~m}$ (1 ha) dan memiliki 5 jalur tanam dan jalur antara sebagai ulangan, seperti dapat dilihat pada Gambar 1. 


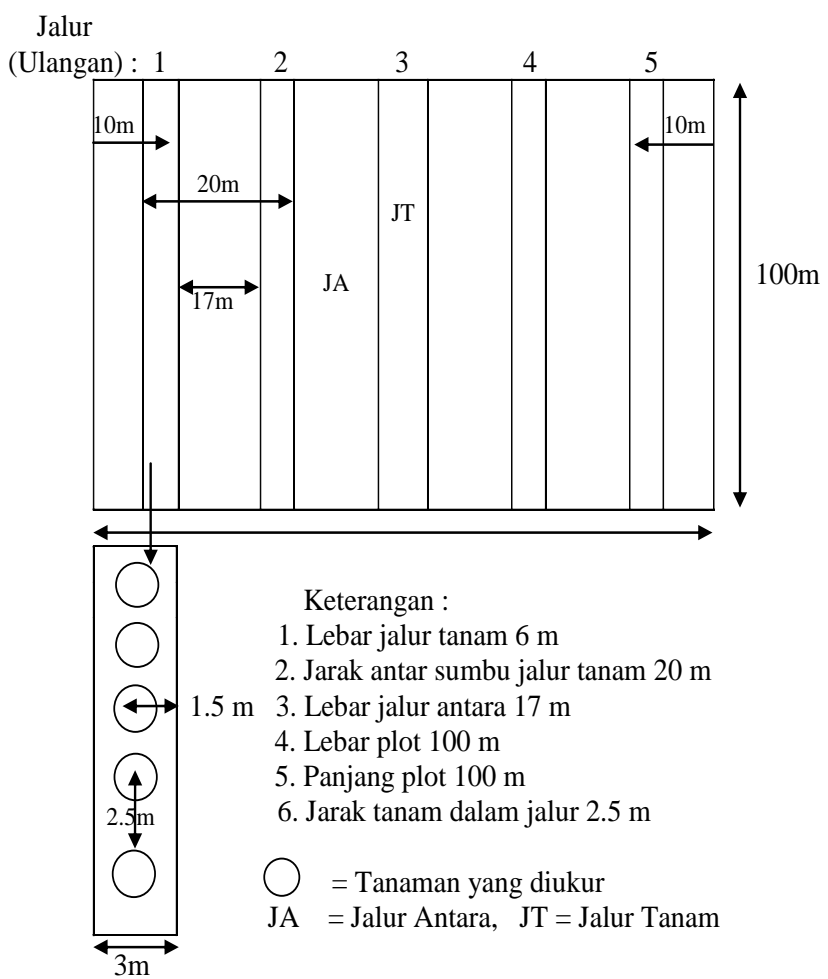

Gambar 1. Lay Out Plot Penelitian

Dari data diameter yang sudah diukur maka parameter pertumbuhan dihitung dengan menggunakan rumus sebagai berikut:

1. Riap Rata-Rata Tahunan (Mean Annual Increament/ MAI)

Perhitungan riap rata-rata tahunan berdasarkan rumus [9] adalah sebagai berikut:

$$
\text { MAI diameter }=\frac{d b h}{u m u r}\left(\frac{c m}{t h n}\right) / \text { umur }
$$

\section{Riap Tahunan Berjalan (Current Annual Increament/CAI)}

Perhitungan riap tahunan berjalan berdasarkan rumus sebagai berikut [10]:

$$
C A I \text { diameter }=\frac{(D n+1)-D n}{(T n+1)-T n}=\Delta D / \Delta T
$$

Untuk mengetahui perbedaan riap diameter tegakan di jalur tanam dengan di jalur antara dilakukan pengukuran riap tegakan pada kedua jalur tersebut di dalam masing-masing PUP dengan 5 kali ulangan.

Selanjutnya uji statistik untuk mengetahui perbedaan riap diameter tegakan di jalur tanam dan di jalur antara dilakukan dengan menggunakan analisis statistik (uji t) sebagai berikut:

$$
\begin{aligned}
S^{2} & =\frac{\left(n_{1}-1\right) S_{12}+\left(n_{2}-1\right) S_{22}}{\left(n_{1}-1\right)+\left(n_{2}-1\right)} \\
S d^{2} & =\frac{\left(n_{1}+n_{2}\right)}{\left(n_{1} n_{2}\right)} S^{2}
\end{aligned}
$$




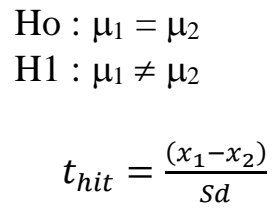

$\mathrm{t}_{\text {hit }}\left\{\begin{array}{l}\leq \mathrm{t}_{\alpha / 2} ;(\mathrm{n} 1+\mathrm{n} 2-2) \text { - terima Ho - tidak ada perbedaan yang signifikan antara } \mu_{1} \text { dan } \mu_{2} \\ >\mathrm{t}_{\alpha / 2} ;(\mathrm{n} 1+\mathrm{n} 2-2)-\text { tolak Ho — ada perbedaan yang signifikan antara } \mu_{1} \text { dan } \mu_{2}\end{array}\right.$

di mana :

$\mu_{1}=$ rataan riap diameter $(\mathrm{cm} / \mathrm{th})$ populasi pada jalur tanam

$\mu_{2} \quad=$ rataan riap diameter $(\mathrm{cm} / \mathrm{th})$ populasi pada jalur antara

$\mathrm{x}_{1}=$ rataan riap diameter $(\mathrm{cm} / \mathrm{th})$ sampel pada plot jalur tanam

$\mathrm{x}_{2}=$ rataan riap diameter $(\mathrm{cm} / \mathrm{th})$ sampel pada plot jalur antara

$\mathrm{S}_{1} \quad=$ varians model plot jalur tanam

$\mathrm{S}_{2} \quad=$ varians model plot jalur antara

$\mathrm{n}_{1} \quad=$ jumlah sampel model plot jalur tanam

$\mathrm{n}_{2} \quad=$ jumlah sampel model plot jalur antara

\section{Hasil dan Pembahasan}

\subsection{Riap di Jalur Tanaman}

Hasil pengukuran diameter tanaman S. Leprosula dan D. lanceolata di jalur tanam yang diperoleh di lapangan dianalisis dan menghasilkan data pertumbuhan diameter dari umur 1 tahun sampai 7 tahun tersaji pada tabel 1. Sedangkan riap diameter tanaman S. Leprosula dan D. lanceolata pada beberapa variasi umur disajikan pada Tabel 2.

Tabel 1. Pertumbuhan Diameter Jenis D. lanceolata dan S. leprosula Berdasarkan Umur Tanaman di Jalur Tanam PUP TPTJ PT BFI

\begin{tabular}{llll}
\hline \multirow{2}{*}{$\begin{array}{l}\text { Umur } \\
(\mathrm{th})\end{array}$} & Rataan diameter & $\begin{array}{l}\text { Rataan } \\
\text { semua jenis }(\mathrm{cm})\end{array}$ \\
\cline { 2 - 3 } & S. leprosula $(\mathrm{cm})$ & D. lanceolata $(\mathrm{cm})$ & 0,0 \\
0 & 0 & 0 & 0,3 \\
2 & 0,3 & 0,3 & 1,5 \\
3 & 1,7 & 1,3 & 3,9 \\
4 & 4,4 & 3,4 & 5,5 \\
5 & 6,8 & 4,2 & 7,0 \\
6 & 8,7 & 5,3 & 8,4 \\
7 & 10,7 & 6,2 & 10,1 \\
\hline
\end{tabular}

Tabel 2. Riap Diameter S. Leprosula umur 1-7 tahun pada Jalur Tanam di PUP TPTJ PT BFI

\begin{tabular}{llll}
\hline \multirow{2}{*}{$\begin{array}{l}\text { Riap } \\
\text { (ke) }\end{array}$} & \multicolumn{2}{c}{ Rataan Riap Diameter $(\mathrm{cm} / \mathrm{th})$} \\
\cline { 2 - 4 } & S. leprosula & D. lanceolata & Semua Jenis \\
\hline 0 & 0 & 0 & 0 \\
2 & 1,4 & 1,0 & 1,2 \\
3 & 2,7 & 1,9 & 2,3 \\
\hline
\end{tabular}




\begin{tabular}{llll}
\hline 4 & 1,9 & 1,1 & 1,5 \\
5 & 2,0 & 0,9 & 1,5 \\
6 & 2,3 & 1,0 & 1,7 \\
\hline Rataan & 2,1 & 1,1 & 1,6 \\
\hline
\end{tabular}

Berdasarkan tabel 1 dan 2 serta berdasarkan hasil pengamatan dari tahun pertama tanaman operasional TPTJ sampai tahun ke tujuh dapat diketahui bahwa $S$. leprosula menunjukkan pertumbuhan dan riap diameter tegakan yang lebih besar dibandingkan $D$. Lanceolata pada jalur tanam. Perbedaan diameter antara jenis S. leprosula dengan $D$. lanceolata semakin besar dengan meningkatnya umur.

Berdasarkan Tabel 2 dapat diketahui bahwa selama periode pengamatan riap, diameter paling besar terjadi pada riap ke 2 yaitu dari umur 2 tahun ke 3 tahun baik pada jenis $S$. leprosula maupun $D$. Lanceolata. Hal ini kemungkinan disebabkan karena pada tahun-tahun awal tersebut perusahaan masih gencar melaksanakan pemeliharaan tanaman secara lengkap dan intensif. Selanjutnya pada tahun ke 4, 5 dan seterusnya pemeliharaan tidak selengkap dan seintensif tahun-tahun sebelumnya.

Pertumbuhan pohon sangat ditentukan oleh interaksi antara tiga faktor, yaitu keturunan, lingkungan dan teknik silvikultur [11]. Faktor yang mempengaruhi besar kecilnya riap suatu tegakan adalah silvikultur, jenis dan kualitas tempat tumbuh [12]. Sedangkan pertumbuhan bidang dasar merupakan hasil dari pertumbuhan diameter. Riap bidang dasar pohon mencapai titik kulminasi lebih lambat dari riap diameternya [13].

\subsection{Riap di Jalur Antara}

Data pengukuran diameter di jalur antara dianalisis dan menghasilkan data riap diameter tegakan jenis komersil dan non komersil pada beberapa variasi kelas diameter seperti yang tersaji pada tabel 3 .

Tabel 3. Riap Diameter Tegakan di Jalur Antara (Jenis Komersil dan Non Komersil) Berdasarkan Kelas Diameter Di Jalur Antara PUP TPTJ PT BFI

\begin{tabular}{|c|c|c|c|c|c|c|}
\hline \multirow{3}{*}{$\begin{array}{l}\text { Kelas Diameter } \\
(\mathrm{cm})\end{array}$} & \multicolumn{2}{|c|}{ Jenis Komersil } & \multicolumn{2}{|c|}{ Jenis Non Komersil } & \multicolumn{2}{|c|}{ Semua Jenis } \\
\hline & & Rataan $\mathrm{Ri}$ & & Rataan Ri & & Rataan Riap \\
\hline & $\mathrm{N}$ & $\begin{array}{l}\text { Diameter } \\
(\mathrm{cm} / \mathrm{thn})\end{array}$ & $\mathrm{N}$ & $\begin{array}{l}\text { Diameter } \\
(\mathrm{cm} / \mathrm{thn})\end{array}$ & $\mathrm{N}$ & $\begin{array}{l}\text { Diameter } \\
(\mathrm{cm} / \mathrm{thn})\end{array}$ \\
\hline $10-19,9$ & 108 & 0,94 & 27 & 0,69 & 135 & 0,89 \\
\hline $20-29,9$ & 39 & 0,92 & 9 & 0,91 & 48 & 0,92 \\
\hline $30-39,9$ & 23 & 0,93 & 4 & 0,50 & 27 & 0,86 \\
\hline $40-49,9$ & 7 & 1,55 & 3 & 1,01 & 10 & 1,39 \\
\hline $50-59,9$ & 4 & 0,96 & 4 & 1,43 & 8 & 1,19 \\
\hline $60 \mathrm{Up}$ & 2 & 1,19 & 0 & 0,00 & 2 & 1,19 \\
\hline \multicolumn{7}{|l|}{ Semua } \\
\hline Klas diameter & 183 & 1,08 & 47 & 0,76 & 230 & 1,07 \\
\hline
\end{tabular}

Berdasarkan Tabel 2, dapat diketahui riap diameter jenis komersil dan non komersil berdasarkan kelas diameter pada jalur antara di PT BFI. Selain itu juga terlihat riap diameter dari setiap kelas diamater untuk masing-masing jenis (komersil dan non komersil) tidak jauh berbeda dari rataan riap diameternya. Artinya secara keseluruhan dari hasil pengamatan perbedaan riap diameter antar kelas diameter sangat kecil atau tidak jauh berbeda, kecuali untuk jenis komersil pada kelas diameter pertengahan $(40 \mathrm{~cm}-49.9 \mathrm{~cm})$ riap diameter agak meningkat dari kelas diameter di bawahnya maupun di atasnya, begitu juga untuk jenis non komersil pada tiga kelas diameter terakhir dan pada 
kelas diameter terbesar/terakhir riap diameter terlihat nol, sebetulnya bukan riap pohonnya yang nol tetapi terlihat jumlah pohonnya yang tidak ada pada kelas diameter tersebut.

Pada umumnya riap tegakan tinggal hutan alam bekas tebangan mempunyai kategori lambat. Menurut [14], ratarata riap tegakan tinggal jenis dipterocarpa yang tidak dipelihara untuk kelas diameter 10-19 cm sebesar 0,64 cm. Ada beberapa faktor yang menghambat pertumbuhannya antara lain jenis yang beragam, faktor genetik, kerapatan yang tidak teratur, intensitas cahaya yang tidak merata, persaingan hara dan faktor lingkungan sekitar seperti suhu, kelembaban, serta faktor biologis yang mendukungnya seperti mikoriza. Jenis-jenis Shorea termasuk jenis unggulan dan mempunyai nilai ekonomis serta termasuk jenis cepat tumbuh (fast growing). Hasil penelitian menunjukkan bahwa rata-rata riap diameter tanaman ini cukup tinggi yaitu berkisar antara $1,28 \mathrm{~cm}-1,71 \mathrm{~cm}$ atau rata-rata $1,44 \mathrm{~cm}$ [15].

Sedangkan hasil penelitian di PT Inhutani I Berau, Kalimantan Timur pada areal bekas penebangan 10 tahun diperoleh pertumbuhan riap diameter tahunan kelompok meranti mempunyai riap diameter tahunan yang lebih tinggi $(0,589-1,330 \mathrm{~cm} / \mathrm{th})$ dibanding dengan kelompok Dipterocarpaceae non meranti $(0,434-0,861 \mathrm{~cm} / \mathrm{th})$ dan kelompok non Dipterocarpaceae $(0,352-0,783 \mathrm{~cm} / \mathrm{th})$ [16].

Pada Tabel 2 juga dapat diketahui bahwa pada sebaran jumlah pohon di PT BFI, jumlah pohon jenis komersil jauh lebih sedikit dibandingkan jumlah pohon jenis non komersil pada setiap kelas diameter. Semakin berkurangnya jenis pohon non komersil disebabkan oleh semakin meningkatnya kebutuhan kayu sementara disisi lain jenis pohon komersil semakin berkurang maka ada pergeseran pemanfaatan kayu non komersil yang tadinya tidak ditebang dan dimanfaatkan menjadi jenis komersil yang ditebang dan dimanfaatkan. Dari sejarah, pemanfaatannya PT BFI sudah lama sekali beroperasi yaitu sejak sebelum tahun tujuh puluhan dan sudah dua kali daur tebang sehingga jenis komersil pun sudah semakin berkurang. Adapun jenis-jenis pohon komersil dan non komersil yang terdapat di jalur antara di PT BFI tersaji pada tabel 4.

Tabel 4. Jenis-jenis Tegakan Tinggal yang Terdapat di Jalur Antara PT BFI

\begin{tabular}{|c|c|c|}
\hline No & Nama Pohon & Suku \\
\hline A & Komersil & \\
\hline 1 & Artocarpus anisaphilus & Moraceae \\
\hline 2 & Artocarpus lanceofolius & Moraceae \\
\hline 3 & Cananga sp & Annonaceae \\
\hline 4 & Dacryodes rostrata & Burseraceae \\
\hline 5 & Dialium undum & Fabaceae \\
\hline 6 & Dipterocarpus $s p$ & Dipterocarpaceae \\
\hline 7 & Durio dulcis & Bombaceae \\
\hline 8 & Dracontomelon dao & Annacardiaceae \\
\hline 9 & Dryobalanops & Dipterocarpaceae \\
\hline 10 & Dyospiros borneensis & Ebenaceae \\
\hline 11 & Eusideroxylon zwageri & Lauraceae \\
\hline 12 & Koompassia exelsa & Caesalpiniaceae \\
\hline 13 & Lagerstromia speciosa & Lytraceae \\
\hline 14 & Litsea & Lauraceae \\
\hline 15 & Octomeles sumatrana & Tentramelaceae \\
\hline 16 & Palaquium sp & Sapotaceae \\
\hline 17 & Polyalthia glauca & Annonaceae \\
\hline 18 & Pterospermum sp & Sterenliaceae \\
\hline 19 & Santiria sp & Burseraceae \\
\hline 20 & Shorea acuminatissima & Dipterocarpaceae \\
\hline
\end{tabular}




\begin{tabular}{lll}
\hline 21 & Shorea parvifolia & Dipterocarpaceae \\
22 & Shorea sp & Dipterocarpaceae \\
23 & Syzygium & Myrtaceae \\
24 & Xanthostmemon & Myrtaceae \\
\hline B & Non Komersil & \\
\hline 1 & Aglaia sp & Meliaceae \\
2 & Lansium $s p$ & Meliaceae \\
3 & Nephelium sp & Sapindaceae \\
4 & Pancholia volida & \\
\hline
\end{tabular}

\subsection{Perbandingan Riap Diameter di Jalur Tanaman dan Jalur Antara}

Dari data riap diameter di jalur tanam maupun di jalur antara maka untuk lebih mudah membandingkan rataan diameter tegakan, riap diameter dan bidang dasar, serta tinggi jenis S. leprosula dan D. lanceolata di jalur tanam dengan tegakan jenis komersil dan non komersil di jalur antara disajikan pada tabel 5.

Tabel 5. Rataan Diameter, Tinggi, Riap Diameter S. Leprosula dan D. Lanceolata Umur 7 Tahun di Jalur Tanam dan Jenis Komersil dan Non Komersil di Jalur Antara PT BFI

\begin{tabular}{lclll}
\hline Lokasi/Jenis & $\mathrm{N}$ & $\begin{array}{l}\text { Rataan } \\
\text { Diameter } \\
\text { umur 7 thn }\end{array}$ & $\begin{array}{l}\text { Rataan } \\
\text { Tinggi } \\
\text { umur 7 thn }\end{array}$ & $\begin{array}{l}\text { Rataan Riap } \\
\text { Diameter } \\
(\mathrm{cm} / \mathrm{thn})\end{array}$ \\
\hline Jalur Tanam & 150 & 13,02 & 1360,03 & 2,08 \\
\hline S. leprosula & 135 & 7,24 & 667,74 & 1,14 \\
D. lanceolata & & & & \\
Semua Jenis & & & & 1,08 \\
\hline Jalur Antara & 183 & 22,29 & 16,06 & 0,65 \\
\hline Komersil & 47 & 22,33 & 14,39 & \\
Non Komersil & & & & \\
Smua Jenis & & &
\end{tabular}

Analisis data statistik dengan memakai uji beda $t$ untuk membandingkan riap diameter antar jenis dan antar jalur hasilnya sebagian besar berbeda signifikan dan sangat signifikan serta sebagian kecil non signifikan atau tidak berbeda nyata. Uji beda riap diameter $S$. leprosula dengan dengan $D$. lanceolata pada jalur tanam dan dengan jenis komersil di jalur antara hasilnya semua berbeda sangat signifikan. Riap S. leprosula juga lebih besar dibanding riap $D$. lanceolata dan secara statistik berbeda signifikan sampai sangat signifikan.

Di jalur tanam intensitas cahaya yang diterima tanaman relatif lebih banyak dibandingkan di jalur antara yang sebagian besar ketersediaan ruang masih tertutup tajuk walaupun bekas tebangan, begitu juga persaingan unsur hara di jalur tanaman relatif lebih sedikit dibanding di jalur antara. Untuk family Dipterocarpaceae umumnya memiliki rataan pertumbuhan yang bervariasi cukup besar. Pada tingkat semai dan pancang umumnya bersifat toleran yang memerlukan cahaya tidak penuh sehingga dapat menunjukkan rata-rata pertumbuhan yang cepat [17].

Dengan bertambahnya umur maka tanaman akan tumbuh menjadi besar, sehingga kebutuhan cahaya dan unsur hara akan meningkat. Dengan jarak tanam yang lebar, ketersediaan ruang, cahaya, dan unsur hara bagi tanaman lebih banyak yang dapat memacu pertumbuhan tanaman. Jarak tanam yang lebar menciptakan ruang masuknya cahaya yang lebih besar. Cahaya merupakan faktor penting terhadap berlangsungnya fotosíntesis, sementara fotosíntesis 
merupakan proses yang menjadi kunci dapat berlangsungnya proses metabolisme yang lain. Fotosíntesis adalah proses dasar pada tanaman untuk menghasilkan makanan dan sumber energi untuk pertumbuhan.

Peningkatan cahaya bagi Shorea parvifolia secara berangsur-angsur akan meningkatkan proses fotosintesis hingga tingkat kompensasi cahaya, yaitu tingkat cahaya pada saat pengambilan $\mathrm{CO} 2$ sama dengan pengeluaran $\mathrm{CO} 2$, apabila cahaya terus menerus meningkat fotosintesis akan terus naik sampai mencapai tingkat cahaya jenuh [18]. Observasi lapang menunjukkan bahwa dipterocarpaceae memerlukan keteduhan parsial dengan perkembangan terbaik pada intenistas cahaya matahari penuh.

Dalam jalur tanam diperoleh hasil riap tumbuh terbaik yang disebabkan oleh kondisi ruang tumbuh yang optimal baik di bagian atas maupun di bagian bawah sehingga proses fotosintesis berjalan lancar yang menghasilkan cadangan makanan tersimpan baik dan diikutsertakan oleh respirasi yang baik pula.

\section{Kesimpulan}

Riap diameter terbesar terdapat pada Shorea leprosula di jalur tanam yaitu sebesar 2,08 cm/tahun dan berbeda sangat signifikan dengan jenis lainnya baik di jalur tanam maupun di jalur antara. Hal ini karena terciptanya kondisi ruang tumbuh yang optimal pada jalur tanam. Sifat genetik S. leprosula merespon kondisi lingkungan dan memberikan pengaruh yang signifikan terhadap pertumbuhan dan riap diameter. Hal ini juga memperlihatkan bahwa intensitas cahaya dan pemeliharaan yang intensif pada tegakan S. leprosula di jalur tanam memberikan pengaruh yang sangat signifikan terhadap peningkatan pertumbuhan dan riap diameter tegakan tersebut. Potensi tegakan di jalur antara masih bisa diharapkan produksi tebangannya untuk menambah hasil panen tanaman di jalur tanam pada saat akhir daur dalam sistem TPTJ.

\section{Referensi}

[1] M.Na'iem, Widiyatmo, M. Zaky Al-Fauzi (2013) "Progeny Test of Shorea leprosula as Key Point To Increase Productivity of Secondary Forest In Pt Balik Papan ForestIndustries, East Kalimantan, Indonesia”, Enviromental Sciences, Procedia, Elsevier B.V. Kyoto University

[2] M. Na'iem (2014) "Peningkatan Produktivitas Hutan Nasional Berbasis Rehabilitasi: Strategi Efisiensi Penggunaan Kawasan Hutan. 50 Tahun Fakultas Kehutanan Universitas Gajah Mada: Darurat Hutan Indonesia; Mewujudkan Arsitektur Baru Kehutanan Indonesia”, Tangerang, Wana Aksara

[3] Soekotjo (2009) “Tenik Silvikultur Intensif (SILIN)”, Yogyakarta, Gajah Mada University Press

[4] de Lacerd A.E.B., Junior F.W.A., Scolforo J.R.S., de Mello J.M., de Oliveira A.D., de Carvalho L.M.T., Calegário A., Filho, A.C.F. (2012) Sustainable forest management of native vegetation remnants in Brazil”, in Martín-García J, Diez JJ (eds) Sustainable Forest Management Case Studies, InTech, Rijecka, Croatia

[5] Widyatno S., Purnomo, Soekotjo, Na'iem M., Hardiwinoto S. (2013) "Growth of selected Shorea spp. in secondary tropical rainforests: the effect of silvicultural treatments to improve the quality of growth Shorea spp.", J Penelitian Hutan Konservasi Alam 8 (4): 373-383.

[6] Subiakto A., Rachmat H.H., Sakai C. (2016) "Choosing native tree species for establishing man-made forest: A new perspective for sustainable forest management in changing world.” Biodiversitas 17: 620-625.

[7] Ministry of Forestry "The Guidance of Silviculture System in The Forest Production Area to Manage Forest Product: No. P.9/VI/BPHA/2009”, Jakarta, Ministry of Forestry

[8] Nguyen-The N., Favrichon V., Sist P., Houde L., Bertault J.G., Fauvet N. (1998) "Growth and mortality patterns before and after logging", in Bertault J.G. and Kadir K. (eds) Silvicultural research in a lowland mixed dipterocarp forest of East Kalimantan, CIRAD-forest, Forda \& PT. Inhutani I, Jakarta

[9] Ruchaemi A. (2016) “Forest Management. Growth and Increment Aspects in Forest Sustainability”, Samarinda, Mulawarman University Press

[10] Prodan M. (1968) "Forest Biometrics", London, Pergamon Press Oxford

[11] Kramer, P.J. and Th. T. Kozlowski (1960) "Physiology of Trees", NewYork, McGraw-Hill Book Company

[12] Lai, A.B. (1960) "Silviculture sistem and forest management", India, Jugal Kishore\&Co.

[13] Ruchaemi, A. (2013) "Ilmu Pertumbuhan Hutan”, Samarinda, Mulawarman University Press

[14] Mawazin dan Suhaendi H. (2012) “The Effect of Tree Spacing on Diameter Growth of 5 Year Old Shorea leprosula Miq." Jurnal Penelitian Hutan dan Konservasi Alam 9 (2: 189-197.

[15] Marsono (1987) dalam Darwo dan Mas'ud, 1993 “Pendugaan Riap Tahunan Rata-Rata dan Potensi Volume Sungkai di Provinsi Riau." Buletin Penelitian Kehutanan 9 (4) Desember 1993.

[16] Susanty, F.H. (2001) “Analisis bentuk struktur tegakan dan model-model riap tegakan dengan Sistem Pemanenan yang berbeda di PT Inhutani I Berau, Kalimantan Timur”, dalam Tesis Magister Ilmu Kehutanan Universitas Mulawarman, Samarinda (Tidak dipublikasikan) 
[17] Ashton, P.S. (1982) “Flora Indo-Malayana.” Seri I. 9 (2): 237 -552.

[18] Daniel T.W/, Helms J.A., Bakers F.S. (1995) “Prinsip-prinsip Silvikultur”, in Marsono D. (pent); Soseno O.H. (ed) Principle Of Silviculture, Jogjakarta, Gadjah mada University Press 